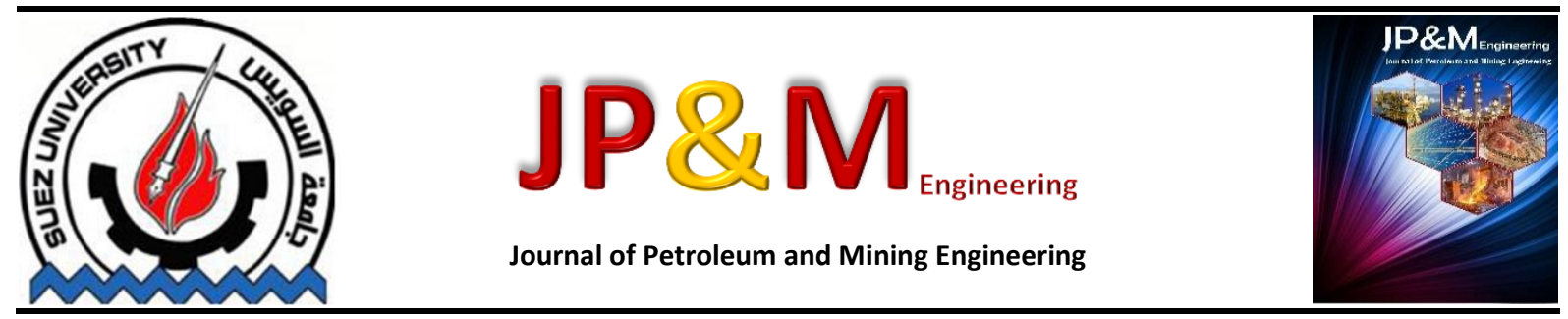

\title{
Improving Oil Displacement Factor by Alkaline Flooding in the DERO Field
}

\author{
Mosab Badr Aldin AlBredi \\ *The Syrian Private University (SPU)- Faculty of Petroleum Engineering - Syria
}

\section{Keywords}

Improved oil recovery, Alkaline Flooding, Oil Displacement Factor and waterflooding.

\begin{abstract}
In this research, a lab study was conducted on the process of injection a solution of Sodium Hydroxide $(\mathrm{NaOH})$ into a lab-prepared a matrix Marble model that physically simulates the reservoir properties of the Jeribeh producing formation in DERO oil field. The Sodium Hydroxide $(\mathrm{NaOH})$ solution is chosen due to its efficiency in studying alkaline. The injection operation of the alkaline was performed on the rock model using the volume ratios $(15,30$ and $50 \%$ PV), (\% PV that represents ratio of the injected liquid to the pores volume of the model), to guarantee an efficient displacement. The injection process was continued at each ratio using the displacement fluid until reaching the $250 \%$ PV level. Through the results of the displacement processes, the change of the following factors in relation with was graphically studied: where, Oil Displacement Factor (O.F.D), Water ratio in the produced fluid, (W) and: ratio of the produced oil volume at every injection process to the accumulated volume of the injected fluid at the same stage, (R.a=V_O/V_T ). To compare the displacement efficiency using Sodium Hydroxide with the efficiency of water injection (currently applied in DERO field), the model was flooded by $(250 \%$ PV) of water after it was cleaned with kerosene, then dried and re-saturated with oil. A comparison between the change of the factors when injecting water and injecting Sodium Hydroxide solution was graphically performed. The results of the graphical comparison of both injection methods implied a steady increase of the (O.F.D) and (R.a) factors and a decrease of the water ratio produced with oil when injecting $(\mathrm{NaOH})$ solution at all the studied injection ratios when compared with water flooding.
\end{abstract}

\section{Introduction}

The main objective of this research is to study the efficiency of alkaline injection $(\mathrm{NaOH})$ to increase the oil displacement factor in Jeribeh-oil-producing formation of the DERO oil field. In this field, water injection has been used to pressure maintenance of this formation and to increase the displacement efficiency as of 1993. Water injection was first started through the DERO -101 oil well and continued at low rates (30 $\mathrm{m}^{3} /$ Day) until 1996 when the injection was performed simultaneously through three wells (101, 102 and 103) at a daily injecting rate of $100 \mathrm{~m}^{3}$ /Day.
In 1998 another well, DERO-8, was added making the number of injected wells four. In 1999, well DERO-104 was drilled and the number of injecting wells became five with an average injection rate of $300 \mathrm{~m}^{3} /$ Day. Currently, a study is being conducted to evaluate the possibility of injecting $\left(500 \mathrm{~m}^{3} /\right.$ Day) in the future, therefore, well DERO-32 was prepared for injecting water separated by the treatment unit and injection was commenced in 2005.

From all above, we can conclude that the annual injected volume of water was $\left(77752 \mathrm{~m}^{3}\right)$, and the accumulated water volume is $\left(658857 \mathrm{~m}^{3}\right)$ against $\left(10703 \times 10^{6} \mathrm{~m}^{3}\right)$ accumulated production of Oil-Water 
fluid which represents a small percentage of no more than $38.5 \%$.

Taking into consideration that DERO field has the following characteristics: geological reserve is (17.064 $\left.\mathrm{x} 10^{6} \mathrm{~m}^{3}\right)$, recoverable reserve is $\left(2.56 \times 10^{6} \mathrm{~m}^{3}\right)$ while oil recovery does not currently exceed $(8.8 \%)$. Oil produced from DERO oil field is considered organicacids-containing oil with $\mathrm{PH}$ suitable for the application of Alkaline flooding method. Screening Criteria for the application of alkaline flooding method is fully compatible with DERO field characteristics regarding formation fluids and reservoir parameters of Jeribeh producing formation as we will see later. For all these reasons, the possibility for applying the alkaline flooding method in this field has been studied.

\section{Significance of the research:}

Importance of this research comes from discussing the application of one chemical EOR in the Syrian oil fields (DERO field). Chemical methods are considered one of enhanced oil recovery methods that have recently received great attention of international petroleum companies.

Application of chemical methods in some of the international fields led to the increase of oil recovery factor. This factor reaches in some reservoirs to more than $25 \%$ of OOIP. This percent is considered high when compared with the other methods. Furthermore, chemical methods are easy to apply as they do not require a lot of sophisticated equipment that other methods such as injecting the wells with $\mathrm{CO}_{2}$ or thermal methods (vapor injection, in-place burning). Also, chemical methods are safe to apply and critical conditions to use these methods are flexible, all that nominates these methods to be applicable in a vast range of fields with different properties. Furthermore, water flooding is currently applied in some Syrian oil field among them the DERO field. Combining chemical methods with water flooding enhances sweeping efficiency more than using water flooding only, thereby oil recovery increases better(2).

\section{Theoretical fundamentals of alkaline injection ${ }^{(3)}$ :}

Using alkaline in the enhanced oil recovery is considered one of relatively easy methods when compared with the rest of chemical methods. Although appeared in the petroleum industry in 1917, alkaline flooding wasn't commonly used like other methods mainly because alkaline have several precautions when applied to carbonate reservoirs. The presence of high concentration of calcium anions may induce charge exchange with alkaline causing deposition of calcium carbonate and calcium hydroxide. These deposits plug the pores of the formation and consequently, decrease its permeability.

Efficiency of this method depends on the following factors that contribute in increasing the oil recovery factor, decreasing the interfacial tension, oil emulsification and wettability change.

\section{Oil classification according to acid number ${ }^{(2)}$ :}

Acid number is defined as the amount of Potassium hydroxide in $(\mathrm{mg})$ required for neutralizing one gram of crude oil.

Oil can be classified into three groups depending on the oil efficiency related to acid number as in table (1):

Table 1: Oil classification according to the Acid Number.

\begin{tabular}{|l|l|l|}
\hline $\begin{array}{l}\text { Oil } \\
\text { classification }\end{array}$ & $\begin{array}{l}\text { Acid } \\
\text { number } \\
\text { (A.N) }\end{array}$ & $\begin{array}{l}\text { Interfacial } \\
\text { tension } \\
\text { (Oil/Alkaline) } \\
\text { (mN/m) }\end{array}$ \\
\hline Low efficient & $\begin{array}{l}0.06- \\
0.25\end{array}$ & $0.05-1$ \\
\hline Efficient & $0.3-1$ & $0.01-0.05$ \\
\hline $\begin{array}{l}\text { Highly } \\
\text { efficient }\end{array}$ & $>1$ & $<0.01$ \\
\hline
\end{tabular}

In alkaline flooding it is necessary to take in consideration the limitation of the alkaline application in oil fields regarding the properties of crude oil, reservoir conditions, oil reserves, special limitation relevant to clay content and formation water salinity and composition.

\section{Case Study:}

(Johnson, Jr) ${ }^{4}$ concluded that alkaline solutions release residual oil stuck at the sandy surfaces through altering wet ability.

To control a displacement process by alkaline, (Alam, M.w, Tiab) ${ }^{5}$ noticed that injecting alkaline with polymer did basically enhance recoverability. Through the displacement tests they performed on core samples, they concluded that there are an ideal concentration and ideal batch volume for each reservoir.

(Trujillo, Edward) ${ }^{6}$ showed through their study that the interfacial tension (IFT) between variety of crude oils and alkaline increases with time as contact surfaces expel the surface efficient materials.

(Trujillo, Edward) ${ }^{6}$ used in their lab-study four types of crude oil (California oil, Wyoming oil, Alaska oil and Illinois oil). Only in the crude oil that has high content of organic acids like the California oil could have a very low (IFT) maintained for a reasonable period, specifically for 24 hours.

In his evaluation of the efficiency of sodium hydroxide and sodium metasilicates as an injecting catalyst in western Canada reservoir, (Larrondo, L.E) ${ }^{7}$ reached to the result that the maximum additional amount of oil was obtained when injecting alkaline solution with volume double of the pores volume with 
(0.3\% WT) of sodium hydroxide and (1\% WT) of sodium metasilicates.

(Surcalo, Harry) $^{8}$ reached the result that the alkaline catalyst injected with surfactants and polymers reduces the chemical absorption of these surfactants and polymers. He also concluded that when salinity is low, the surface efficient material will concentrate in the water phase, while when salinity is considerably high, the surface efficient material will move to the oil phase. The ideal case is that when this material concentrates on the (oil-water) contact which occurs within narrow range of salinity.

(Campbell, Thomas) ${ }^{9}$ performed a comparison between initial washing regimes with alkaline and light saline water to eliminate ions of hardness off the formation water. They reached to important results that high alkaline chemical materials like sodium orthosilicate and sodium hydroxide were highly efficient in eliminating hardness ions off formation water. The excessive displacement with light formation water that followed the highly alkaline initial washing basically showed that no ion exchange occurred, and level of hardness ion stayed at zero in the flowing stream. The same effect was noticed for sodium silicates, but it took a larger volume of the solution to reduce levels of hardness ion to zero in the flowing stream.

(Kurmrine, P.H) ${ }^{10}$ classified using of alkaline chemical materials in the enhanced oil recovery to the following forms: as an initial washing catalyst, with polymers, with surfactants and as an essential production catalyst. He also referred that deposition reactions of multivalent hardness ions with alkaline can be avoided in the injection wells by using appropriate initial washing and/or by using high quality diluted water.

(Tsay, Franks) ${ }^{11}$ showed that the participation between alkaline and acidic oil can lead to additional oil production about (20-25\%) more than using the traditional water flooding within a low range of capillary number. This result has been reached by injecting alkaline within core samples after applying water flooding.

(Cheng.K.h) ${ }^{12}$ indicated that consumption of the chemical materials in alkaline flooding may by decreased by using $\left(\mathrm{Na}_{2} \mathrm{CO}_{3}\right)$ compared with sodium hydroxide and sodium silicates, moreover, using $\left(\mathrm{Na}_{2} \mathrm{CO}_{3}\right)$ provided additional advantage when contact with hard water when carbonate deposits that formed reversely did not affect

permeability when compared with hydroxides or silicates deposits, therefore, using $\left(\mathrm{Na}_{2} \mathrm{CO}_{3}\right)$ for alkaline flooding will result in shorter penetration time of alkaline and increasing the oil recovery factor.

(French, T.R) ${ }^{13}$ showed that using alkaline with surfactants reduces the adsorption of these surfactants onto the rock surface. In the same time, it enables using lower concentrations of these surfactants. He also indicated that the reservoir must not contain or at least contains little amount of gypsum. PH of the reservoir must be higher than (4.5) to be nominated for alkaline flooding.
(A reverse five-spot injecting regime were chosen to be applied on a (10 acre) experimental area in Gujarat Indian oil field. in 1987 an initial wash was performed by injecting (10\%) of pores volume with sodium carbonate. In 1988 (20\%) of pores volume of (0.25 WT) sodium hydroxide was injected, followed by water drive as of March 1989 where (23\%) additional oil was produced from this experimental area) ${ }^{14}$.

In their lab study about diluted alkaline solutions to enhance oil recovery factor of one of gulf of Mexico fields, (M.Pineda, IslasJudrez) ${ }^{15}$ saturated cylindrical samples with $\left(0.8928 \mathrm{gr} / \mathrm{cm}^{3}\right)$ of oil with acid number of $(1.2 \mathrm{mg} \mathrm{KOH} / \mathrm{gr} \mathrm{OIL})$. Alkaline were injected at rate ( $25 \mathrm{ml} / \mathrm{hr}$ ) so approximately one-foot displacing speed was guaranteed. Reservoir conditions were also applied in the experiment. The empirical results showed that oil recovery factor can be higher than (50\%) when injecting alkaline comparing with seawater injections.

(Martin, J.Oxley) ${ }^{16}$ in their study about the effect of various alkaline on the phase behavior of the (oil/formation water/surface efficient material) mixtures showed that phase behavior of the studied system is sensitive for the cation type of the added alkaline. Potassium has a greater effect than that of sodium, while ammonium has the lowest. They also concluded that phase behavior is not sensitive for alkaline anions.

(J.H.Burk) $)^{17}$ concluded that $\left(\mathrm{Na}_{2} \mathrm{CO}_{3}, \mathrm{NaOH}\right.$ and $\mathrm{Na}_{4} \mathrm{SiO}_{4}$ ) alkaline have an equivalent efficiency and the high (PH) value (higher than 11.5) is not essential for chemical (EOR) methods related to alkaline. Also $\left(\mathrm{Na}_{2} \mathrm{CO}_{3}\right)$ has a lower corrosive impact than $(\mathrm{NaOH})$ and $\left(\mathrm{Na}_{4} \mathrm{SIO}_{4}\right)$.

(C.E.cook, P.A.kolodzie) ${ }^{18}$ concluded that acceptable limit of the acid number of oil that allows using alkaline as an injecting method (Alkaline Flooding) is (1 $\mathrm{mg} \mathrm{KOH} / 1 \mathrm{gr}$ Oil).

(Thomasc.campble) ${ }^{19}$ indicated that alkaline play a double role in the (EOR) operations.

The first role is: by creating a high alkaline environment for creating organic soap that reduces the IFT (oil/alkaline solution).

The second role is: by reducing adsorption of surfactants on the rock surface.

For the first role, sodium hydroxide and sodium silicates. For the second role, the order is sodium silicates $>$ sodium hydroxide $>$ sodium carbonate.

(B.garrett, vankirk) ${ }^{20}$ indicated that alkaline flooding needs high quality light water, therefore, ion exchange was widely performed in many fields of California for alkaline flooding at hardness levels of $(2,000 \mathrm{ppm})$ where sodium cation is used to replace ( $\mathrm{Ca}$ and $\mathrm{Mg}$ ) on zeolite or organic gum.

(E.H.mayer, R.L,Berg) ${ }^{21}$ showed that alkaline injection is very complicated process for oil production as production via alkaline flooding leads to the following reactions:

- Reaction between oil and alkaline.

- Reaction between alkaline and rock. 
- Chemical deposition resulted from mixing the alkaline solution with the hardness ions of the formation water.

(Martin)22 found that for sodium alkaline materials, sodium silicates have the lowest effect and sodium carbonate have a moderate effect while sodium hydroxide have the best effect.

(A.M.Attia) ${ }^{23}$ also concluded through studying the phase behavior that miscibility (oil/water) enhances when using $(\mathrm{NaOH})$ more than that when using $\left(\mathrm{Na}_{2} \mathrm{CO}_{3}\right)$.

\section{A brief description of the DERO oil field:}

The DERO field is located ( $36 \mathrm{Km}$ ) to the north of Deir Ezzor city in an individual uplift called Tharo uplift. This structure was first discovered in 1934 by geologists (T.F.Williamson, F.E.Willing). The two geologists conducted a geological survey in the area for which they produced a geological map. In the geological map, the structure appears as group of domes with a trend like the trend of Al-Bishri Mountain. At the top of the structure, Lower-Fares formation appears while Upper-Fares depositions appear in the northern slop of the structure.

\section{Litho-stratigraphic description of Jeribeh formation:}

Depending on the study of the cores taken from this formation, Jeribeh can be divided into the following intervals:

- (JE1): the rocks of this interval consist of micritecalcite-carbonate, while micrite-dolomite is less abundant. Rocks of this interval also contain knots of anhydrite in addition to crystals of pyrite. Thickness of this interval ranges from $(39 \mathrm{~m})$ in DERO-6 well and $(33.5 \mathrm{~m})$ in DERO-15 well.

- (JE2): Rocks of this interval consist of calcite rocks of bio-micro-sparite, in addition to dolomite and dikes of anhydrite. Thickness of this interval is $(20 \mathrm{~m})$ in DERO-8 well and (12 m) in DERO-18 well. (JE3): a (2 $\mathrm{m})$ layer of anhydrite.

- (JE4): consists of calcite biomicrite rocks, sometimes dolomitic. Thickness of this interval is $(28 \mathrm{~m})$ in DERO-5 well and $(23.5 \mathrm{~m})$ in DERO-2\&6 wells.

\section{Petrographic and depositional characteristic of Jeribeh formation:}

Three intervals from bottom upwards can be distinguished:

- (JE1): consists of micrite carbonate rocks. Microscopic calcite forms (70\%) of the total rock volume. Reservoir properties of the studied rocks are medium. Porosity (10-15\%), pore size (0.02-0.8 $\mathrm{mm})$. few vertical millimeter-size cracks can be noticed.

- (JE2): consists of calcite-micosparitic rocks. It consists of microsparitic calcite, sometimes micrite between (50-60\%) of the calcitic rock. Porosity (15$25 \%)$, pores size between $(0.02-1.5 \mathrm{~mm})$ with the presence of cavities up to ( $9 \mathrm{~mm})$.
- (JE3): a (2-4 m) anhydrite layer with poor reservoir properties and no existence of any oil shows.

- (JE4): rocks of this interval consist of micritic-calcite to dolomite- microsparite. Micrite and microsparitic rocks form (50-80\%) of the total rock volume. Reservoir properties of this interval are generally poor in the upper section and good in the lower section.

Figures (1\&2) show the structural map of Jeribeh formation in DERO oil field.

\section{Reservoir indexes of DERO oil field:}

Presented in table (2).

\section{Intersecting the critical conditions for applying alkalines injection with the producing formation and formation fluids in DERO field:}

Characteristics of DERO field are presented in table (3).

Through the intersection of critical conditions for applying alkaline flooding with characteristics of DERO filed, we found that this method is applicable in DERO field for the following reasons:

1. It is obvious from table (3) that characteristics of DERO field are completely conformed with conditions of using alkaline flooding method.

2. Interferences of gypsum, anhydrite and shale within the producing interval are very little as we see in the lithological description of the producing formation.

3. Production from DERO field was from Jeribeh formation that is describes as: cavernous fractured porous carbonates rock with little faults and fractures as we will see later.

4. DERO field has a good porosity about (22\%) (1).

5. Presence of $\left(17.064 \times 10^{6} \mathrm{~m}^{3}\right)$ as a geological reserve and $\left(2.56 \times 10^{6} \mathrm{~m}^{3}\right)$ as a recoverable reserve ${ }^{(1)}$.

6. Good residual reserve about $\left(2.407 \times 10^{6} \mathrm{~m}^{3}\right)^{(1)}$.

7. Current recovery factor is poor, it does not exceed $(8.8 \%)$ despite the high density of the wells network (91.4\%) (currently working wells are 37) (1).

8. Water flooding is currently applied in this field to support formation pressure which is considered and auxiliary factor to apply this alkaline flooding method. Water flooding however is not sufficient currently and in the future for many reasons related to reduction of oil recovery factor.

9. $\mathrm{PH}$ of $\mathrm{DERO}$ field is alkaline $(\mathrm{PH} \approx 8.5)$ which is very suitable for applying the said method.

10. Percent of $\left(\mathrm{CO}_{2}\right)$ in the formation water of the said field is zero as shown by the analysis results of the associated formation water. Absence of $\mathrm{CO}_{2}$ contributes in increasing the efficiency of this flooding method. Analysis results are presented in table (4).

11. Percent of mineral ions in the formation water is suitable for applying this method as it is shown in table (4). 


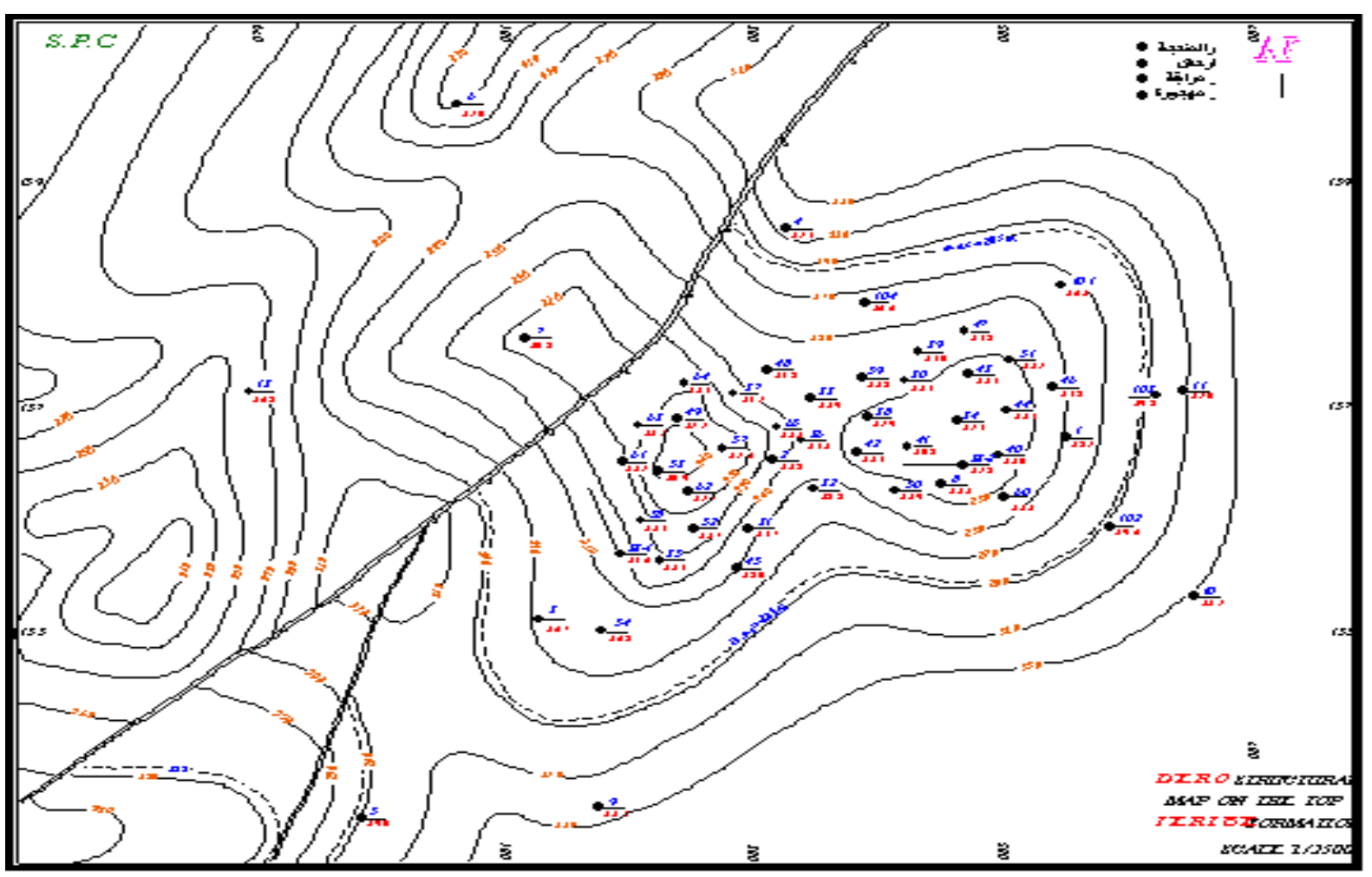

Figure 1 structural map of DERO field (Jeribeh formation) (1).

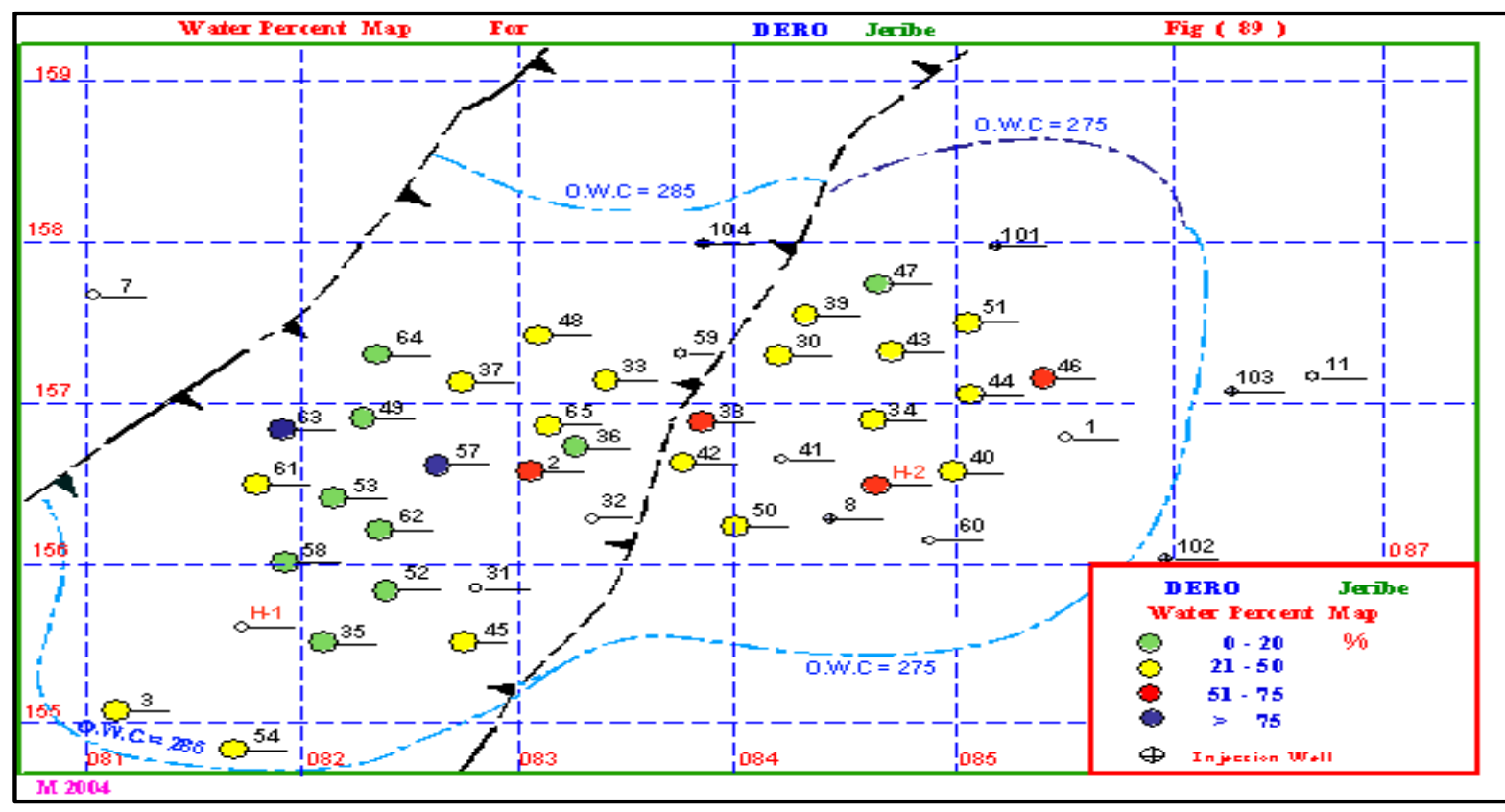

Figure 2 DERO oil wells (ratio of the produced water) (1). 
Table 2: Reservoir indexes of DERO oil field (1).

\begin{tabular}{|c|c|c|}
\hline Formation & Jeribeh & transition \\
\hline Active thickness & \multicolumn{2}{|l|}{$4.55 \mathrm{~m}$} \\
\hline Average oil saturation until the end of 2008 & \multicolumn{2}{|l|}{$65 \%$} \\
\hline API & \multicolumn{2}{|l|}{35.1} \\
\hline Oil viscosity at surface conditions & \multicolumn{2}{|l|}{15.5 C.P } \\
\hline Initial oil recovery & \multicolumn{2}{|l|}{$15 \%$} \\
\hline Current oil recovery & \multicolumn{2}{|l|}{$8.8 \%$} \\
\hline Recoverable reserve & $1.299 .10^{6} \mathrm{~m}^{3}$ & $2.56 .10^{6} \mathrm{~m}^{3}$ \\
\hline Geological reserve & $8.662 .10^{6} \mathrm{~m}^{3}$ & $17.064 .10^{6} \mathrm{~m}^{3}$ \\
\hline Current water ratio until the end of 2008 & \multicolumn{2}{|l|}{$34.5 \%$} \\
\hline Initial formation pressure & \multicolumn{2}{|l|}{$54 \mathrm{~atm}$} \\
\hline Current formation pressure & \multicolumn{2}{|l|}{45.5 atm } \\
\hline Formation temperature & \multicolumn{2}{|l|}{$33^{\circ} \mathrm{C}$} \\
\hline Total number of wells & \multicolumn{2}{|l|}{59} \\
\hline Number of producing wells & \multicolumn{2}{|l|}{34} \\
\hline Number of operating wells & \multicolumn{2}{|l|}{37} \\
\hline Accumulative oil production & \multicolumn{2}{|c|}{$1.507685 .10^{6} \mathrm{~m}^{3}$} \\
\hline Residual reserve & \multicolumn{2}{|l|}{$2.407 .10^{6} \mathrm{~m}^{3}$} \\
\hline Density of wells network & \multicolumn{2}{|l|}{91.4} \\
\hline Rate of Yearly suction & \multicolumn{2}{|l|}{$2.2 \%$} \\
\hline Rate of depletion & \multicolumn{2}{|l|}{$58.9 \%$} \\
\hline Formation description & \multicolumn{2}{|c|}{ fractured cavernous porous carbonates rock } \\
\hline Formation depth & \multicolumn{2}{|l|}{$600 \mathrm{~m}$} \\
\hline
\end{tabular}


Table 3: Comparison between characteristic of DERO field and the condition for applying alkaline injecting method.1

\begin{tabular}{|c|c|}
\hline Conditions to apply this method & Characteristics of DERO Field \\
\hline $\mathrm{API}>\mathbf{2 0}$ & API $=35.1$ \\
\hline$\mu<35$ (C.P) & $\begin{array}{l}\mu(\text { surface })=15.5 \text { C.P }\left(30^{\circ} \mathrm{C}\right) \\
\mu(\text { formation })=4.5 \text { C.P }\end{array}$ \\
\hline$S_{0}>35 \%$ & Current $S_{0}=65 \%$ \\
\hline $\mathrm{K}>10$ (m.D) & $K=89.6(m . D)$ \\
\hline Depth $<9000(\mathrm{ft})$ & Depth $=600 \mathrm{~m}$ \\
\hline Temperature less $200 \mathrm{~F}$ & $\mathrm{~T}=33^{\circ} \mathrm{C}=91.4^{\circ} \mathrm{F}$ \\
\hline h (m) N.C & $\mathrm{h}=4.55 \mathrm{~m}$ \\
\hline $\begin{array}{l}\text { Acceptable percent of organic acids in } \\
\text { the oil expressed by the Acid Number }\end{array}$ & Acid Number $=0.95\left(\mathrm{mg}_{\text {кон }} / \mathrm{goil}\right)$ \\
\hline
\end{tabular}

Table 4: Analysis results of the associated water sample (produced water) taken from DERO field (1).

\begin{tabular}{|c|c|c|}
\hline Index & Value & Unit \\
\hline $\mathrm{Ca}^{++}$ & 141.0 & $\mathrm{mg}_{\text {eq }} / \mathrm{l}$ \\
\hline $\mathrm{Mg}^{++}$ & 163 & $\mathrm{mg}_{\mathrm{eq}} / \mathrm{l}$ \\
\hline $\mathrm{Na}^{+}+\mathrm{K}^{+}$ & 2690.3 & $\mathrm{mg}_{\mathrm{eq}} / \mathrm{l}$ \\
\hline Total Cations & 2994 & $\mathrm{mg}_{\text {eq }} / \mathrm{l}$ \\
\hline $\mathrm{Cl}^{-}$ & 2989 & $\mathrm{mg}_{\mathrm{eq}} / \mathrm{l}$ \\
\hline $\mathrm{HCO}_{3}^{-}$ & 5 & $\mathrm{mg}_{\mathrm{eq}} / \mathrm{l}$ \\
\hline $\mathrm{SO}_{4}^{--}$ & 0 & $\mathrm{mg}_{\mathrm{eq}} / \mathrm{l}$ \\
\hline Total Anions & 2994.3 & $\mathrm{mg}_{\mathrm{eq}} / \mathrm{l}$ \\
\hline $\mathrm{H}_{2} \mathrm{~S}$ & 429 & Ppm \\
\hline $\mathrm{PH}$ & 8.5 & - \\
\hline T.D.S & 82 & $g / l$ \\
\hline D.O & 43 & $\%$ \\
\hline $\mathrm{CO}_{2}$ & 0 & $\%$ \\
\hline
\end{tabular}




\section{Experimental Work:}

\section{First: choosing the most efficient alkaline for field application:}

This study was conducted on the following types of alkalines:

In order to choose the most efficient type for field application, the relation between the followings factor and alkaline concentration in the solution $\left(C_{A}\right)$ was studied:

- Solution acidity (PH).

- Turbidity (TUR).

- Conductivity (CON).

- Interfacial tension (IFT).

The above relations were studied to choose the alkaline type that achieves:

1) The minimum (IFT) at oil contact by using a minimum concentration.

2) The best values of ( $\mathrm{PH}, \mathrm{TUR}$ and $\mathrm{CON})$.

$\checkmark$ Proposed concentrations for studying each alkaline are: $(0.5,0.7,1,1.5$ and 2$) \%$ WT.

$\checkmark \quad$ (KRUSS K10) device for measuring the (IFT).

$\checkmark \quad(\mathrm{HAACH})$ device for measuring the (PH) and (CON).

$\checkmark$ (HAACH2100P) device for measuring the (TUR).

All the measurements were performed at formation temperature $\left(33^{\circ} \mathrm{C}\right)$. Results are presented in the following tables and charts:

\section{Discussing the results:}

Results of studying the five types of alkalines are summarized in table (11):

The following principles must be taken into consideration when choosing the suitable alkaline:

- The alkaline must achieve a minimum (IFT) at the contact with oil at the minimum concentration $\left(C_{A}\right)$ corresponding to the critical molecular concentration (CMC).

- At this concentration, alkaline must give high electrical conductivity expressed by (CON) measurement.

- Must not cause forming any salty deposits when reacted with mineral ions in the formation.

- Turbidity degree of the solution must be as low as possible at the critical molecular concentration (CMC).

- PH of alkaline solution must be highly alkaline to increase its efficiency in removing hardness ions off the formation water. it must also reduce the quantity of the surfactant lost by adsorption.

According to these principles, we found that only $\mathrm{NaOH}$ and $\mathrm{Na}_{4} \mathrm{SiO}_{4}$ alkaline from the studied types meet these criteria. $\mathrm{NaOH}$ shows minimum (IFT), maximum electrical conductivity and $\mathrm{PH}$ at concentration ( $0.5 \% \mathrm{WT}$ ), while turbidity degree of $\mathrm{NaOH}$ solution at that concentration is (113 NTU) which is considered an acceptable degree. For $\left(\mathrm{Na}_{4} \mathrm{SiO}_{4}\right)$ alkaline, its (IFT) value at $(0.5 \% \mathrm{WT})$ concentration is the same as the $(\mathrm{NaOH})$, but the $\mathrm{PH}$ and electrical conductivity are less compared with the $\mathrm{NaOH}$. Solution of the $\left(\mathrm{Na}_{4} \mathrm{SiO}_{4}\right)$ alkaline shows higher turbidity degree at $(0.5 \% \mathrm{WT})$ when compared with $\mathrm{NaOH}$.

According to the above, the alkaline $(\mathrm{NaOH})$ will be chosen for the following lab study.

Table 5: types of the studied alkalines.

\begin{tabular}{|c||l|}
\hline \hline ALK1 & \multicolumn{1}{|c|}{$\mathrm{NaOH}_{\text {(sodium hydroxide) }}$} \\
\hline \hline ALK2 & $\mathrm{NaHCO}_{3}$ (sodium bicarbonate) \\
\hline \hline ALK3 & $\mathrm{Na}_{4} \mathrm{SiO}_{4}$ (sodium orthosilicate) \\
\hline \hline ALK4 & $\mathrm{Na}_{5} \mathrm{P}_{3} \mathrm{O}_{10}$ (Benta sodium triphosphate) \\
\hline \hline ALK5 & $\mathrm{C}_{6} \mathrm{H}_{15} \mathrm{NO}_{3}$ (triethanolamine) \\
\hline
\end{tabular}


Table 6: Measurements results of (ALK 1).

\begin{tabular}{|c|c|c|c|c|}
\hline $\begin{array}{l}\text { Alkaline concentration } \\
\text { in the solution }\end{array}$ & $\mathbf{P H}$ & $\begin{array}{l}\text { CON } \\
(\mathrm{ms} / \mathrm{cm})\end{array}$ & $\begin{array}{l}\text { TUR } \\
\text { (NTU) }\end{array}$ & $\begin{array}{l}\text { IFT } \\
\text { (mN/M) }\end{array}$ \\
\hline 0.5 & 11.5 & 23.3 & 113 & 0.4 \\
\hline 0.7 & 11.8 & 32.9 & 140 & 0.4 \\
\hline 1 & 11.9 & 45.0 & 116 & 0.4 \\
\hline 1.5 & , 11.9 & 68 & 73 & 0.3 \\
\hline 2 & $\begin{array}{r}11.9 \\
\Lambda \\
\end{array}$ & 88.6 & 20 & 0.3 \\
\hline
\end{tabular}

Table 7: Measurements results of (ALK 2)

\begin{tabular}{|c|c|c|c|c|}
\hline $\begin{array}{c}\text { Alkaline concentration } \\
\text { in the solution }\end{array}$ & PH & $\begin{array}{c}\text { CON } \\
(\mathbf{m s} / \mathbf{c m})\end{array}$ & $\begin{array}{c}\text { TUR } \\
\text { (NTU) }\end{array}$ & $\begin{array}{c}\text { IFT } \\
(\mathbf{m N} / \mathbf{M})\end{array}$ \\
\hline 0.5 & 8.11 & 4.61 & 24 & 5.8 \\
\hline 0.7 & 8.15 & 6.07 & 24 & 5.5 \\
\hline 1 & 8 & 8.38 & 30 & 5.25 \\
\hline 1.5 & 8.04 & 11.91 & 41 & 4.8 \\
\hline 2 & 8.07 & 15.26 & 35 & 4.3 \\
\hline
\end{tabular}

Table 8: Measurements results of (ALK 3)

\begin{tabular}{|c|c||c||c||c||}
\hline $\begin{array}{c}\text { Alkaline concentration } \\
\text { in the solution }\end{array}$ & PH & $\begin{array}{c}\text { CON } \\
(\mathbf{m s} / \mathbf{c m})\end{array}$ & $\begin{array}{c}\text { TUR } \\
(\mathbf{N T U})\end{array}$ & $\begin{array}{c}\text { IFT } \\
(\mathbf{m N} / \mathbf{M})\end{array}$ \\
\hline 0.5 & 10 & 7.33 & 230 & 0.4 \\
\hline 0.7 & 10.10 & 9.81 & 371 & 0.4 \\
\hline 1 & 10.20 & 13.28 & 477 & 0.4 \\
\hline 1.5 & 10.32 & 18.0 & 530 & 0.2 \\
\hline 2 & 10.38 & 23.4 & 532 & 0.2 \\
\hline
\end{tabular}

Table 9: Measurements results of (ALK 4)

\begin{tabular}{|c|c||c|c||c||}
\hline \hline $\begin{array}{c}\text { Alkaline } \\
\text { concentration } \\
\text { in the solution }\end{array}$ & PH & $\begin{array}{c}\text { CON } \\
(\mathbf{m s} / \mathbf{c m})\end{array}$ & $\begin{array}{c}\text { TUR } \\
\text { (NTU) }\end{array}$ & $\begin{array}{c}\text { IFT } \\
(\mathbf{m N} / \mathbf{M})\end{array}$ \\
\hline \hline 0.5 & 8.21 & 4.11 & 4 & 8 \\
\hline 0.7 & 8.15 & 5.34 & 4 & 7.8 \\
\hline 1 & 8.13 & 7.02 & 6 & 7.4 \\
\hline
\end{tabular}




\begin{tabular}{|c|c|c|c|c|}
\hline \hline 1.5 & 8.08 & 9.53 & 6 & 6.8 \\
\hline 2 & 8.01 & 11.89 & 6 & 7.4 \\
\hline
\end{tabular}

Table 10: Measurements results of (ALK 5)

\begin{tabular}{|c|c|c||c|c|}
\hline $\begin{array}{c}\text { Alkaline concentration } \\
\text { in the solution }\end{array}$ & PH & $\begin{array}{c}\text { CON } \\
(\mathbf{m s} / \mathbf{c m})\end{array}$ & $\begin{array}{c}\text { TUR } \\
\text { (NTU) }\end{array}$ & $\begin{array}{c}\text { IFT } \\
(\mathbf{m N} / \mathbf{M})\end{array}$ \\
\hline 0.5 & 7.72 & 452 & 79 & 5.4 \\
\hline 0.7 & 7.97 & 450 & 78 & 5.2 \\
\hline 1 & 8.20 & 449 & 102 & 4.8 \\
\hline 1.5 & 8.38 & 449 & 135 & 4.6 \\
\hline 2 & 8.51 & 449 & 138 & 4.3 \\
\hline
\end{tabular}

Table 11: Summary of the studying results of the six studied alkalines.

\begin{tabular}{|c|c|c|c|c|c|c|}
\hline $\begin{array}{l}\text { Type of the } \\
\text { alkaline }\end{array}$ & $\begin{array}{c}\text { IFT } \\
(\mathrm{mN} / \mathrm{M})\end{array}$ & $\begin{array}{c}\text { CMC } \\
(\% \mathbf{W t})\end{array}$ & $\begin{array}{c}\mathrm{CON} \\
\left(\mu_{\mathrm{S}} / \mathrm{cm}\right)\end{array}$ & PH & $\begin{array}{c}\text { TUR } \\
\text { (NTU) }\end{array}$ & Remarks \\
\hline ALK1=NaOH & 0.4 & 0.5 & $23.3 \times 10^{9}$ & 11.5 & 113 & \multirow{5}{*}{$\begin{array}{l}\text { CON: electrical conductivity of the solution } \\
\text { corresponding to the critical molecular } \\
\text { concentration. } \\
\text { TUR: turbidity degree of the solution } \\
\text { corresponding to the critical molecular } \\
\text { concentration. } \\
\text { PH: acidity of the solution corresponding to } \\
\text { the critical molecular concentration. } \\
\text { IFT: Interfacial tension corresponding to the } \\
\text { critical molecular concentration. } \\
\text { CMC: critical molecular concentration }\end{array}$} \\
\hline ALK2=NaHCO3 & 25.8 & 0.5 & $4.61 \times 10^{9}$ & 8.11 & 24 & \\
\hline ALK3=Na4SiO4 & 0.4 & 0.5 & $7.33 \times 10^{9}$ & 10 & 230 & \\
\hline ALK4=Na5 $\mathrm{P}_{3} \mathrm{O}_{10}$ & 8 & 0.5 & 4.11 & 8.21 & 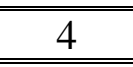 & \\
\hline $\begin{array}{c}\text { ALK5= } \\
\mathrm{C}_{6} \mathrm{H}_{15} \mathrm{NO}_{3}\end{array}$ & 5.4 & 0.5 & 452 & 7.72 & 79 & \\
\hline
\end{tabular}

First: results of alkaline flooding process:

The following figures represent the graphical presentation of the results: $\mathrm{T}=33^{\circ} \mathrm{C}$

- $\Delta \mathrm{P}=3 \mathrm{~atm}$

- P1=45 atm

- $\mathrm{P} 2=42 \mathrm{~atm}$

- $\mathrm{C}_{\mathrm{A}}=0.5 \% \mathrm{Wt}$

Second: preparation of a rock model that physically simulates Jeribeh producing formation of DERO field:

Preparation of this rock model was explained in my previous research published in Petroleum and Mining Journal in 2016 under the title of:

"Effect of ASP Chemical Flooding Efficiency on Displacement Factor and Water Percentage After
Exhaustion of Water Flooding Efficiency in DERO Field"

As a reminder, the model consists of a mix of marble grains with the following ratios and dimensions:

- $89 \%$ wt of marble grains with dimensions between $\mu \mathrm{M} 63<$ (Marble) $<\mu \mathrm{M} 75$.

- $11 \% w t$ of marble grains with dimensions between $\mu \mathrm{M} 75<$ (Marble) $<\mu \mathrm{M} 150$.

Third: preparing the formation oil sample:

It is known that the formation oil has specific density, viscosity and surface tension, therefore, during the lab tests. dead oil taken from the field must not be used. Hence, an oil sample that has the 
same properties of the formation oil must be prepared.

Based on the published research, I came to the result that the ideal kerosene ratio must be added to the surface oil sample of DERO field to give an equivalent viscosity of the DERO oil at formation conditions is $\left(C_{K}=19.5 \%\right.$ vol $)$.

\section{Fourth: Model saturation with oil:}

Procedures of this stage were explained in the research.

Fifth: injection operations:

The following injecting operations were performed on the oil-saturated model:

- $\mathrm{NaOH}$ flooding with the following volume ratios:(15, 30 and 50$) \%$ PV, then injection continued at each ratio with the displacement fluid (water) up to (250\% PV).

- Water flooding with (250\% PV) for the comparison with the efficiency of alkaline flooding.

Results of these measurements are shown in the following figures:

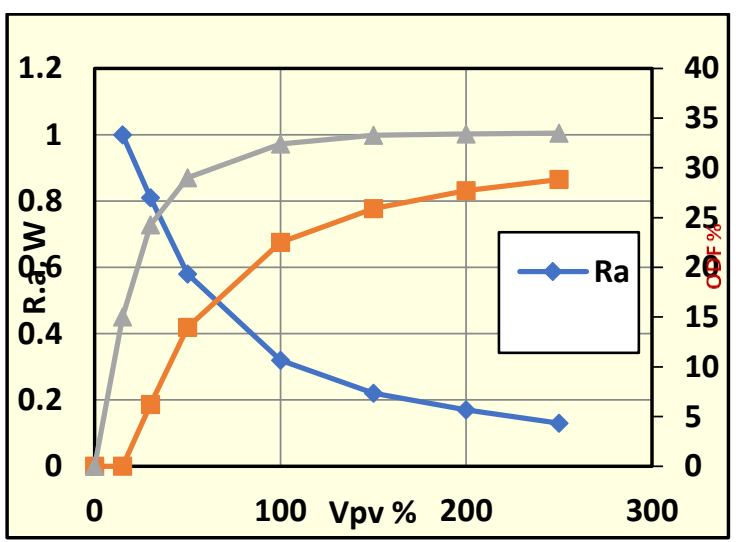

Figure 3: change of (O.D.F, R.a, W) in relation with (Vpv\%)

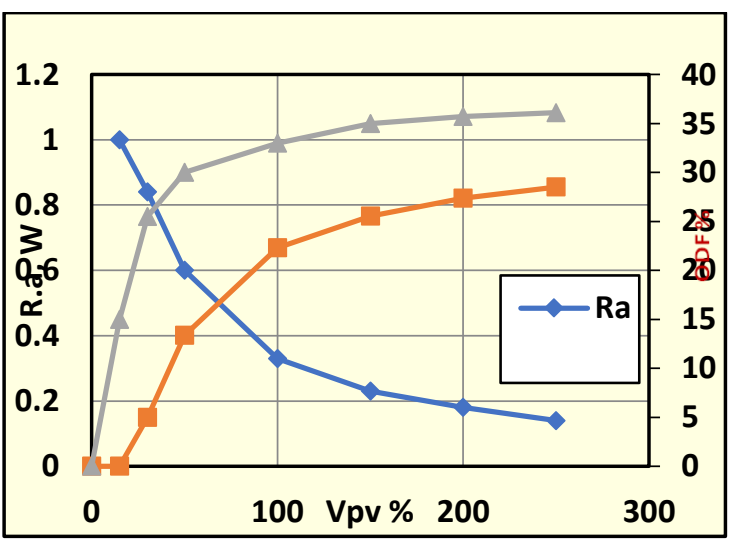

Figure 4: change of (O.D.F, R.a, W) in relation with (Vpv\%)

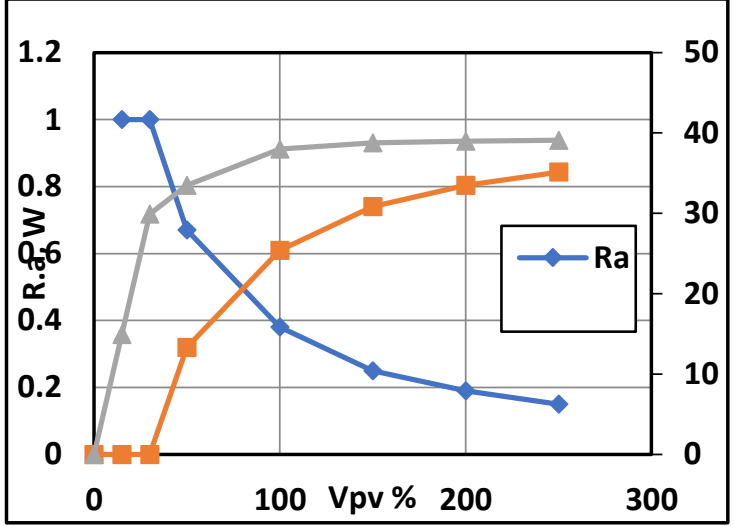

Figure 5: change of (O.D.F, R.a, W) in relation with (Vpv\%)

At all the injection ratios of the alkaline, graphical presentation is as in the following figures:

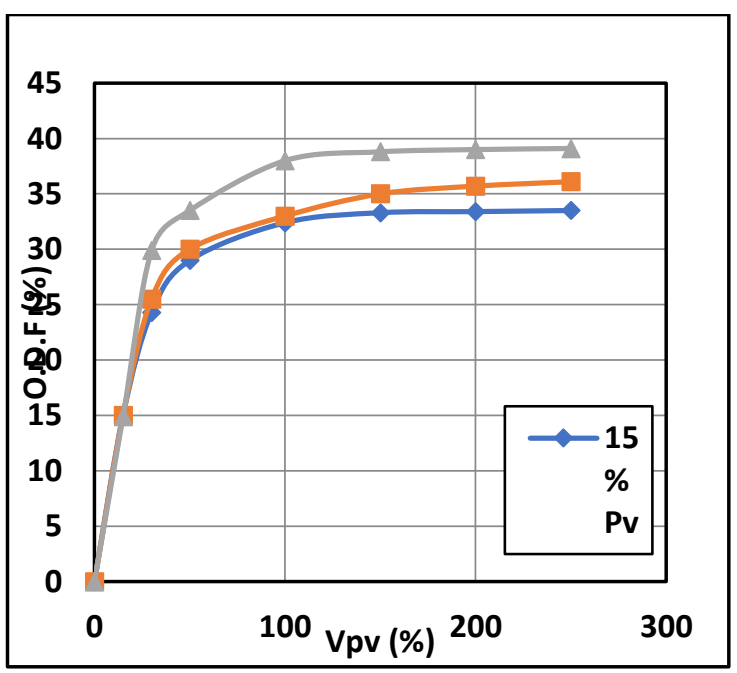

Figure 6: change of (O.D.F) in relation with (Vpv\%) when injecting $\mathrm{NaOH}$ at all the injected ratios.

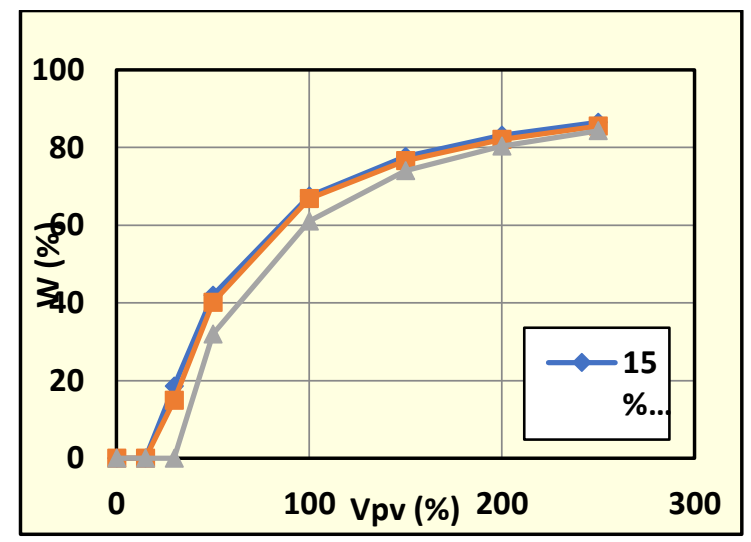

Figure 7: change of (W) in relation with (Vpv\%)when injecting $\mathrm{NaOH}$ at all the injected ratios. 


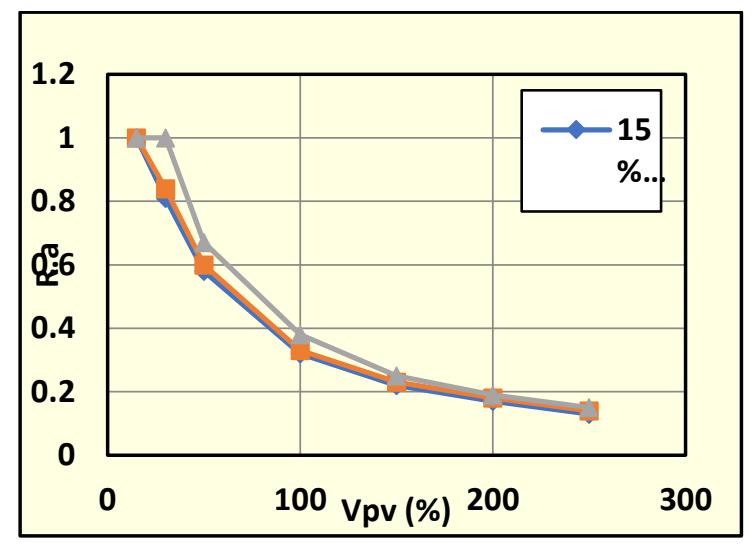

Figure 8: change of (R.a) in relation with (Vpv\%) when injecting $\mathrm{NaOH}$ at all the injected ratios.
Results of the water flooding:

As in the following figures:

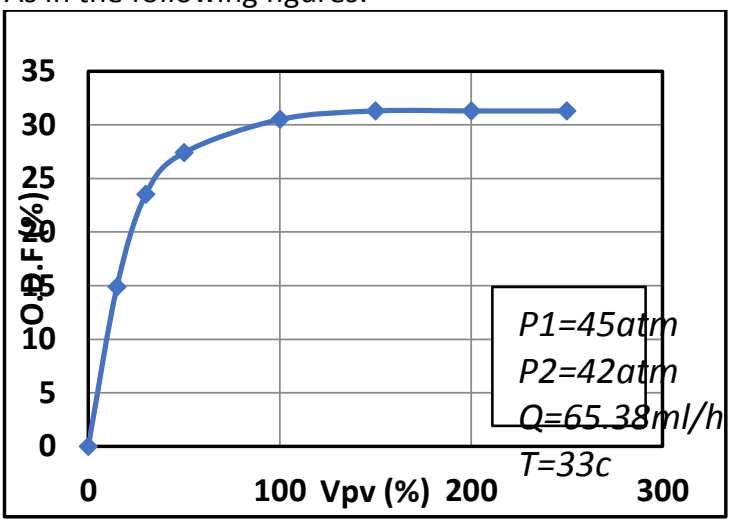

Figure 9: change of (O.D.F) in relation with (Vpv\%) during water flooding.

Summary of the $\mathrm{NaOH}$ injection results:

\begin{tabular}{|l|l|l|l||l|}
\hline $\begin{array}{l}\text { Percent of the injected efficient- } \\
\text { material volume to the pores } \\
\text { volume \%Pv }\end{array}$ & $\begin{array}{l}\text { O.D.F(max) } \\
\boldsymbol{\%}\end{array}$ & $\begin{array}{l}\mathbf{W}(\mathbf{m a x}) \\
\boldsymbol{\%}\end{array}$ & R.a(max) & R.a(min) \\
\hline $\mathbf{1 5}$ & 33.5 & 86.5 & 1 & 0.13 \\
\hline $\mathbf{3 0}$ & 36.1 & 85.5 & 1 & 0.14 \\
\hline $\mathbf{5 0}$ & 39.1 & 84.3 & 1 & 0.15 \\
\hline
\end{tabular}

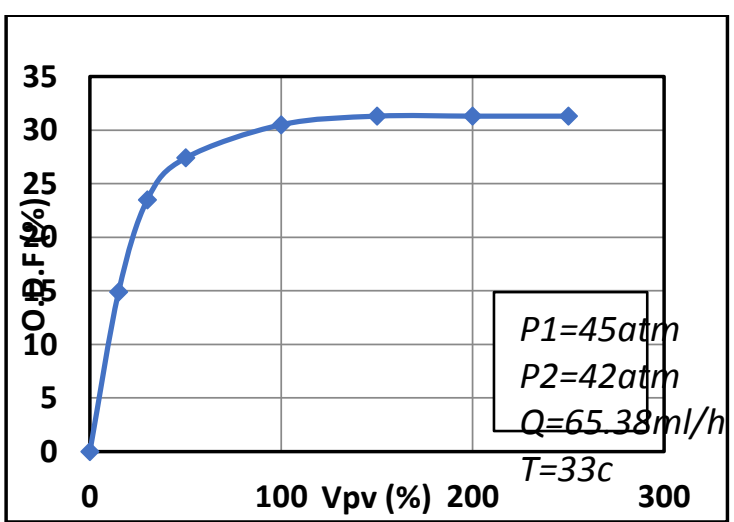

Figure 9: change of (O.D.F) in relation with (Vpv\%) during water flooding.

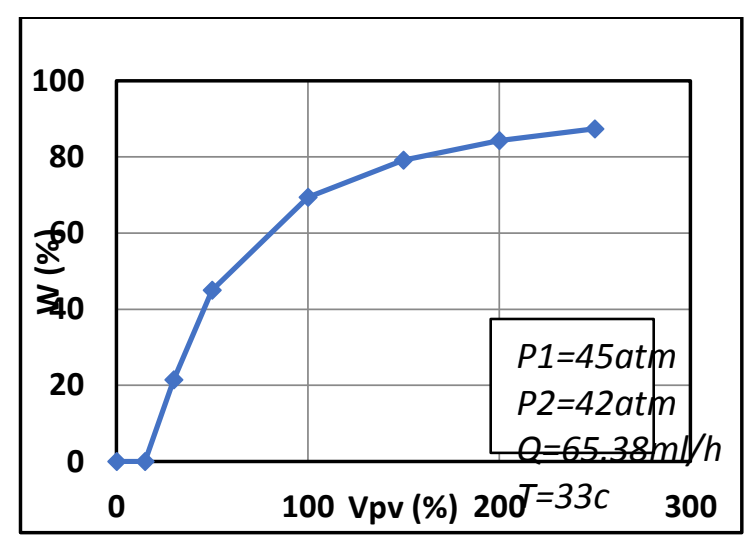

Figure 10: change of $(\mathrm{W})$ in relation with $(\mathrm{Vpv} \%)$ during water flooding. 


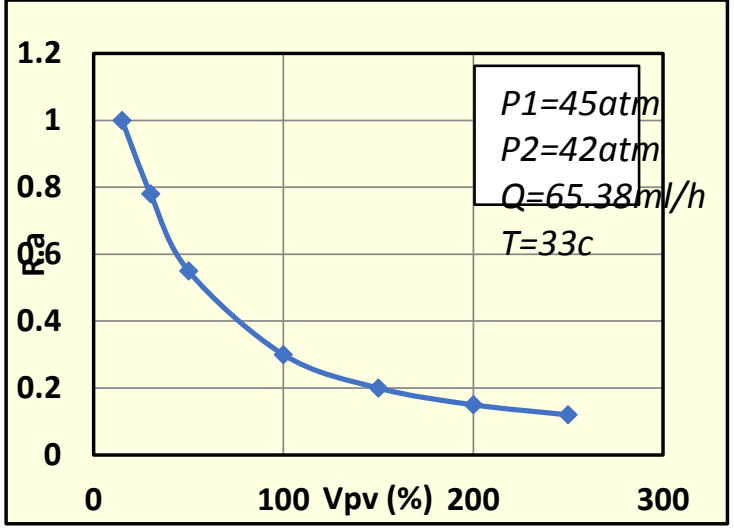

Figure 11: change of (R.a) in relation with (Vpv\%) during water flooding.

\section{Comparison between the efficiency of water} flooding and alkaline flooding:

First: regarding the change of displacement factor:

It is shown in table (16).

Results are charted and presented in the following figures:

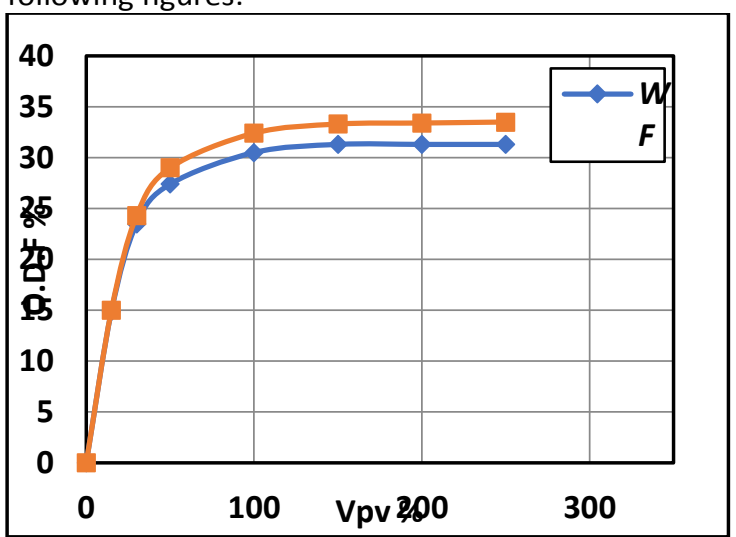

Figure 12: comparison between (O.D.F) change in relation with (Vpv\%) during water flooding and alkaline flooding at (15\%PV).

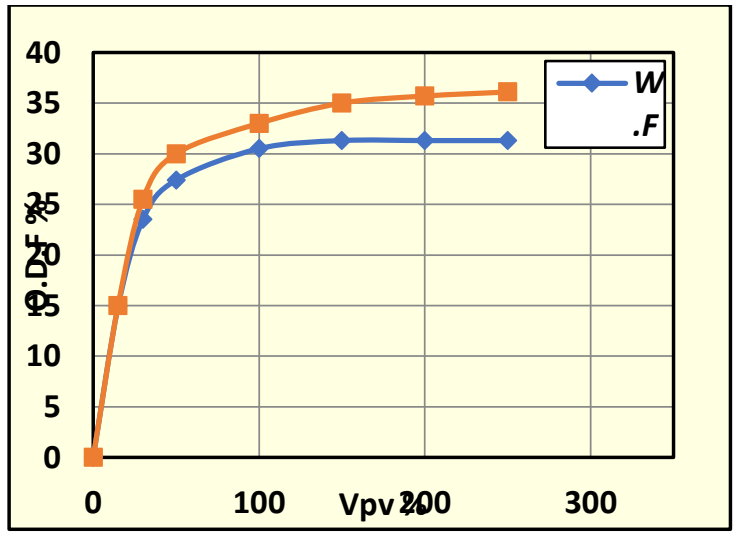

Figure 13: comparison between (O.D.F) change in relation with ( $\mathrm{Vpv} \%$ ) during water flooding and alkaline flooding at (30\%PV).

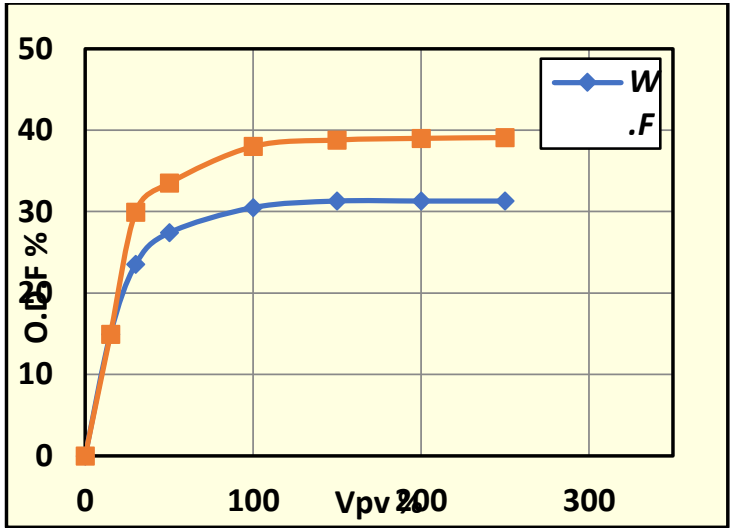

Figure 14: comparison between (O.D.F) change in relation with (Vpv\%) during water flooding and alkaline flooding at (50\%PV).

Second: regarding the ratio change of the produced water with oil:

Results are presented in table (17).

Third: regarding the change of (R.a) factor:

Results are presented in table (18). 
Table: 16: results of (O.D.F) change in relation with (Vpv\%) for water flooding-Alkaline flooding

\begin{tabular}{|c|c|c|c|c||}
\hline Vpv\% & $\begin{array}{c}\text { O.D.F\% } \\
\text { Water }\end{array}$ & $\begin{array}{c}\text { O.D.F\% } \\
\text { NaOH(15\% } \\
\text { V) }\end{array}$ & $\begin{array}{c}\text { O.D.F\% } \\
\text { NaOH(30\%P } \\
\text { V) }\end{array}$ & $\begin{array}{c}\text { O.D.F\% } \\
\text { NaOH(50\%P } \\
\text { V) }\end{array}$ \\
\hline \hline $\mathbf{0}$ & 0 & 0 & 0 & 0 \\
\hline $\mathbf{1 5}$ & 14.9 & 15 & 15 & 14.9 \\
\hline $\mathbf{3 0}$ & 23.5 & 24.3 & 25.5 & 29.9 \\
\hline $\mathbf{5 0}$ & 27.4 & 29 & 30 & 33.5 \\
\hline $\mathbf{1 0 0}$ & 30.5 & 32.4 & 33 & 38 \\
\hline $\mathbf{1 5 0}$ & 31.3 & 33.3 & 35 & 38.8 \\
\hline $\mathbf{2 0 0}$ & 31.3 & 33.4 & 35.7 & 39 \\
\hline $\mathbf{2 5 0}$ & 31.3 & 33.5 & 36.1 & 39.1 \\
\hline \hline
\end{tabular}

Table 17: results of (W) change in relation with (Vpv\%) for water flooding and alkaline flooding.

\begin{tabular}{|l|l|l|l|l||}
\hline Vpv\% & $\begin{array}{l}\text { W\% } \\
\text { W.F }\end{array}$ & $\begin{array}{l}\text { W\% } \\
\text { NaOH(15\%P } \\
\text { V) }\end{array}$ & $\begin{array}{l}\text { W\% } \\
\text { NaOH(30\%P } \\
\text { V) }\end{array}$ & $\begin{array}{l}\text { W\% } \\
\text { NaOH(50\%P } \\
\text { V) }\end{array}$ \\
\hline $\mathbf{0}$ & 0 & 0 & 0 & 0 \\
\hline $\mathbf{1 5}$ & 0 & 0 & 0 & 0 \\
\hline $\mathbf{3 0}$ & 21.5 & 18.6 & 14.9 & 0 \\
\hline $\mathbf{5 0}$ & 45 & 41.9 & 40.1 & 32 \\
\hline $\mathbf{1 0 0}$ & 69.4 & 67.5 & 66.9 & 61 \\
\hline $\mathbf{1 5 0}$ & 79.1 & 77.7 & 76.6 & 74 \\
\hline $\mathbf{2 0 0}$ & 84.3 & 83.2 & 82.1 & 80.4 \\
\hline $\mathbf{2 5 0}$ & 87.4 & 86.5 & 85.5 & 84.3 \\
\hline
\end{tabular}


Table (18): results of (R.a) change in relation with (Vpv\%) for water flooding and alkaline flooding.

\begin{tabular}{|c|c|c|c|c|}
\hline Vpv\% & $\begin{array}{c}\text { R.a } \\
\text { W.F }\end{array}$ & $\begin{array}{c}\text { R.a } \\
\mathbf{N a O H}(\mathbf{1 5 \%} \mathbf{P} \\
\mathbf{V})\end{array}$ & $\begin{array}{c}\text { R.a } \\
\mathbf{N a H ( 3 0 \% \mathbf { P }} \\
\mathbf{V})\end{array}$ & $\begin{array}{c}\text { R.a } \\
\mathbf{N a O H}(\mathbf{5 0} \% \mathbf{P} \\
\text { V) }\end{array}$ \\
\hline \hline $\mathbf{1 5}$ & 1 & 1 & 1 & 1 \\
\hline $\mathbf{3 0}$ & 0.78 & 0.81 & 0.84 & 1 \\
\hline $\mathbf{5 0}$ & 0.55 & 0.58 & 0.60 & 0.67 \\
\hline $\mathbf{1 0 0}$ & 0.30 & 0.32 & 0.33 & 0.38 \\
\hline $\mathbf{1 5 0}$ & 0.2 & 0.22 & 0.23 & 0.25 \\
\hline $\mathbf{2 0 0}$ & 0.15 & 0.17 & 0.18 & 0.19 \\
\hline $\mathbf{2 5 0}$ & 0.12 & 0.13 & 0.14 & 0.15 \\
\hline
\end{tabular}

\section{General discussion of alkaline flooding Results:}

At all studied injecting ratios of sodium hydroxide solution $(15,30$ and 50$)$ \%PV we notice an obvious increase of the displacement factor (O.D.F) (higher than that when water flooding) until injecting around $(100 \%)$ of the pores volume with the flooding fluid $(\mathrm{NaOH}$ solution + displacement fluid). Later, the increase of O.D.F continues but in lower pace (at the injection ratios $30,50 \% \mathrm{PV}$ ) while (O.D.F) value becomes steady at injection rate (15\%PV). Also (O.D.F) value becomes steady when water flooding.

For the (R.a) factor, we notice that its value stays steady and maximum (equals 1 ) at an injection rate of the $\mathrm{NaOH}$ solution equals $(50 \% \mathrm{PV})$ then it starts to gradually decrease. (R.a) value starts to decrease as of its maximum value at the $\mathrm{NaOH}$ solution injection ratio of (15.3\%PV), the same case happens when water flooding.

It is noticed that (R.a) value when injecting $\mathrm{NaOH}$ solution stays higher than that when water flooding at all the studied injecting ratios of $\mathrm{NaOH}$ solution.

Regarding the change of water ratio in the produced fluid, it is noticeable that when injecting $\mathrm{NaOH}$ solution with ( $50 \% \mathrm{PV}$ ) this ratio is zero until the ration of $(30 \% \mathrm{PV})$ then this ration starts increasing, while ratio of water in the produced fluid (when injecting $\mathrm{NaOH}$ solution with $(15,30 \% \mathrm{PV}))$ starts to increase after the ratio (15\%PV) with the notice that ratio of the produced water with oil when injecting $\mathrm{NaOH}$ solution at all injecting ratios is less than that when water flooding.

All above can be explained due to the important and active role that $\mathrm{NaOH}$ plays depending on its influence on the oil displacement process through the model by decreasing the interfacial tension caused by the reaction between the organic acids in oil with the injected alkaline that leads to forming an in-place surfactant (carboxylic soap) which in turn contributes in the increase of displacement efficiency and consequently increase the amount of the swept oil.

Oil emulsifying process, occurring in the presence of alkaline, also plays a significant role in increasing the displacement factor. Forming of emulsion increases the formation relative permeability of oil. Consolidating of the oil emulsion droplets leads to a higher saturation with oil and the formed emulsions has a suitable viscosity that help displacing material motility to become close to that of the displaced material. In addition to the above, the vital and efficient role that alkaline plays in wet ability alteration.

As we mentioned at the beginning of this research, the efficiency of oil recovery deepened on altering wet ability of rock from oil wet into water wet. the amount of produced oil increases by Wet ability alteration can be achieved in reservoirs that are naturally oil-wet by the adsorption of the natural surfactant (carboxylic soap). This is due to the impact of surface ions on the properties of oil wet ability. Local wet ability depends on the final distribution of oil and water on the rock surface. Stability of the water membrane formed between the oil and rock is considered a major factor in the alteration of rock wet ability. The unstable membrane causes the polar components in oil to be distributed at the rock surface for the oil wet ability occurs. Formation of a stable water membranes depends on the resistant forces occur between the negative surface charges on the contact surface (rock-water) and (water-oil) that leads the water membrane to stick on the rock surface due to vandervals forces. Results refer here that adhesion 
of the water membrane on the rock surface is related to the $\mathrm{PH}$ and momentum of the ion. It was found that the higher the $\mathrm{PH}$ caused by alkaline, the higher the stability and adhesion of this water membrane which sweeps the oil layer adsorbed on the rock surface by which it increases the amount of the produced oil.

\section{Conclusions}

According to the positive lab results reached in this study, alkaline flooding method can be accredited as a method to increase the oil displacement factor in DERO field. Through the reached results, we suggest injecting $\mathrm{NaOH}$ solution with (50\%PV) as this ratio achieved better indexes than the rest of the studied ratios. It is recommended to apply this method on a mini-model (pilot) in the studied field and monitoring the outcome of this process in the field. As encouraging results are reached, then this method can be generalized and applied on the entire field.

Conducting following researches aiming to study the possibility of applying alkaline flooding method on other fields that have characteristics compatible with the critical conditions to apply this method.

\section{Defining terminology used in the previous tables and figures:}

1. Vpv: ratio of the injected liquid volume to the pores volume (\%).

2. $\mathbf{V}_{\mathrm{A}}$ : amount of the relative volume of the injected liquid (ml)

3. $\mathbf{V}_{\mathbf{T}}$ : accumulated volume of the injected liquid (ml).

4. Vo: accumulated volume of the produced oil ( $\mathrm{ml})$.

5. Vw: accumulated volume of water produced with oil (ml)

6. O.D.F: oil displacement factor (\%).

7. W: percentage of water in the produced liquid (oil + water) $\left(\mathrm{W} \%=\mathrm{V}_{\mathrm{w}} / \mathrm{V}_{\mathrm{T}} .100\right)$.

8. R.a: proposed factor (recoverability) represents the ratio between accumulated volume of produced oil in every injecting process and the accumulated volume of the injected liquid in the same stage $(\mathrm{ml} / \mathrm{ml}):\left(R a=\frac{\mathrm{V}_{\mathrm{O}}}{\mathrm{V}_{\mathrm{T}}}\right)$.

9. P1: model inlet pressure (45 atm) equals the average formation pressure of DERO oil field.

10. P2: model outlet pressure (42 atm) equals the average bottom-hole pressure of DERO producing wells.

\section{References}

[1] Reports of the reservoir engineering directorateJbiseh field directorate 2010.

[2] PHD. Mosab AlBredi, "Enhanced Oil Recovery-2" Al-Furat University- 2017.

[3] Organization of Arab Petroleum Exporting Countries (OAPEC) "Enhanced Oil Recovery", Kuwait-2009.

[4] JohmsonJr "Status Of Caustic And Emulsion Methods" Journal Of Petroleum Technology 1976.
[5] Alm, M.W, Tiab "Mobility Control Of Caustic Flood" SPE 1985

[6] Trujillo, Edward M "The Static and Dynamic Interfacial Tensions Between Crude Oil And Caustic Solutions" SPE 1983.

[7] LarrOndo, L.E "Laboratory Evaluation of Sodium Hydroxide, Sodium Ortho Silicate, And Sodium Meta Silicate as Alkaline Flooding Agents for Western Canada Reservoir" SPE 1985.

[8] Surkalo, Harry "Enhanced Alkaline Flooding" SPE 1990.

[9] Campbell, Thomas C "Chemical Flooding: A Comparison Between Alkaline and Soft Saline Reflash Systems for Removal of Hardness Ions from Reservoir Brines" SPE 1979.

[10] Krumrine, P.H "Scale Formation During Alkaline Flooding" Journal of Petroleum Technology 1985

[11] Tsay, Frank S "Laboratory Study on The Use of Alkaline Flood Recovery Mechanisms in Water Flooded Oil Reservoirs" SPE 1985.

[12] Cheng.K.H "Chemical Consumption During Alkaline Flooding: A Comparative Evaluation" SPE 1986.

[13] French,T.R"Design and Optimization of Alkaline Flooding Formulations" Oklahoma 1990.

[14] Goyal, K.L, S.: Paul, A.K "Performance Evaluation of Caustic Pilot Project of North Gujarat Oil Field, India" Bahrain 1991.

[15] M.Pineda, Islas Juarez "injection Of Dilute Alkaline Solutions to Improve the Recovery Factor in Oil- Wet Reservoirs" Mexico 1996.

[16] Matrine, J. Coxly "Effect of Various Alkaline Chemicals on Phase Behavior of Surfactant/Oil/Brine Mixtures" SPE 1985.

[17] J.H.Burk "Comparison Of Sodium Carbonate, Sodium Hydroxide, And Sodium Ortho Silicate For EOR" SPE 1987.

[18] C.E.Cooke, P.A.Kolodzie "Oil Recovery by Alkaline Water Flooding" SPE 1974

[19] Thomas C.Campbell "The Role of Alkaline Chemicals in The Recovery of Low Gravity Crude Oils" SPE 1982.

[20] B.Garrett, Vankirk"Alkaline Flooding- Design of A Low Cost, Portable Facility" SPE 1983.

[21] E.H.Mayer,R.L,Berg"Alkaline Injection for Enhanced Oil Recovery" Journal of Petroleum Technology 1983

[22] Martine,F.D,Oxely,J.C,AndLim "Enhanced Recovery of Sans Crude Oil with a Combination on Surfactant and Alkaline Chemicals" Las Vegas 1985

[23] A.M.Attia "Phase Behavior of surfactant/oil/water system in enhanced oil recovery"1995. 
